\title{
Detection System of Slag Entrained to Teeming Stream in Continuous Casting*
}

\section{Introduction}

In a continuous casting process, it has been desired to detect slag entrained to a teeming stream from a ladle to a tundish under sealed condition in order to protect molten steel from reoxidization.

Sumitomo Metal Industries, Ltd. has developed "Detection System of Slag Entrained to Teeming Stream" which enables to detect slag in the teeming stream effectively by an optical method. This system has been tested at the continuous casting process in Wakayama Steel Works, and is now employed at Wakayama and $\mathrm{Ka}$ shima Steel Works.

\section{Principle and Feature}

The principle of the slag detection is based on the difference in emissivity and a stream diameter between slag and steel. Both the emissivity and the stream diameter of slag are larger than those of steel.

The features of this system are very simple probe structure and easy operation.

\section{Measuring System}

Schematic diagram of this system is shown in Fig. 1. A probe is inserted into a sealing refractory tube which is set under the ladle. Infrared radiation from the teeming stream is transmitted to an optical powermeter (Sensor: Si photodio- de, Wave length: about $0.85 \mu \mathrm{m}$ ) by an optical rod and a bundle of optical fibers in the measurement probe. A measured optical signal is transformed into an electrical signal by the optical powermeter and the electrical signal is processed by a microcomputer.

The detection system is automatically activated when molten steel weight in the ladle reaches the pre-set minimum weight. An alarm signal is given when the mean value and the standard deviation of the measured value exceed the threshold levels which are calculated when the system is started or the ladle sliding nozzle is moved.

\section{Experimental Results}

The test was carried out in Wakayama Steel Works. The optical power when slag entrained to the teeming stream were compared with that of steel 30 times, then the threshold levels were decided. The mean value of the optical power from slag is about 1.6 times of that from molten steel only. Its mean value from molten steel mixed with slag is about 1.2 times of that from molten steel only. (Fig. 2) A typical result of the measurement and the judgement is shown in Fig. 3. The timing of alarm outputs from the system were compared with the timing of visual detection about 150 times. About

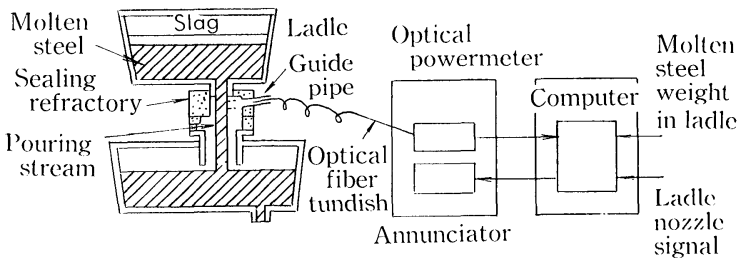

Fig. 1. Schematic system diagram.
$80 \%$ of alarm output timing appeared in 5 sec before visual detection, and the other alarm outputs were also given before visual detection. And successful results were also obtained from all of the 26 sealing pour tests without visual detection.

\section{Conclusion}

The detection system of slag entrained to the teeming stream by the optical method in the continuous casting process which uses shrouding tube was developed. It is confirmed that this system is useful for on-line use.

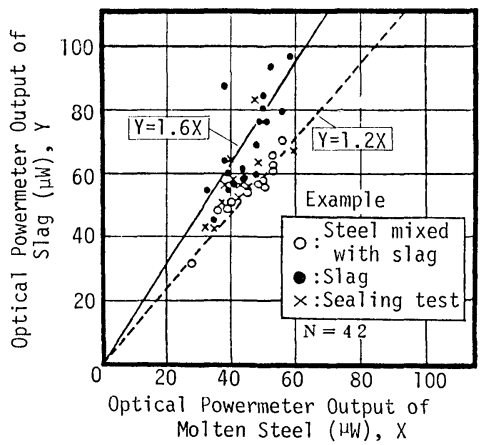

Fig. 2. Relation between optical power from molten steel and that from slag.

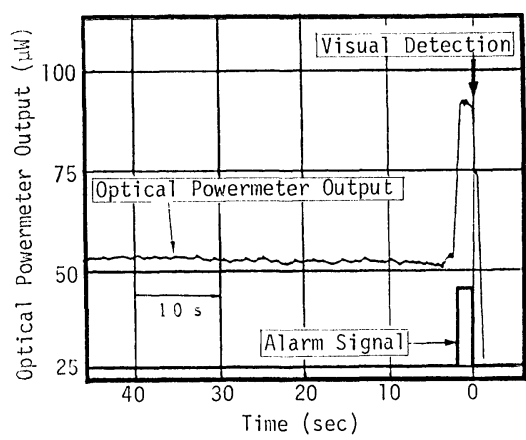

Fig. 3. Typical result of measurement.

\footnotetext{
* For further information, write to Instrumentation and Control Technology Center, Sumitomo Metal Industries, Ltd., 1-3, Nishinagasuhondori, Amagasaki 660. (C) 1986 ISIJ
} 